\title{
Substituição do milho pelo sorgo em dietas para juvenis de pacu
}

\author{
Milena Souza dos Santos Sanchez ${ }^{(1)}$, Marcelo dos Santos Nascimento(1) e Hamilton Hisano(2)
}

(1)Universidade Estadual do Oeste do Paraná, Rua da Faculdade, no 645, Jardim Santa Maria, Caixa Postal 320, CEP 85903-000 Toledo, PR, Brasil. E-mail: milenasanchezzoo@hotmail.com, marc.elopesca@hotmail.com ${ }^{(2)}$ Embrapa Meio Ambiente, Rodovia SP-340, Km 127,5, Caixa Postal 69, CEP 13820-000 Jaguariúna, SP, Brasil. E-mail: hamilton.hisano@embrapa.br

Resumo - O objetivo deste trabalho foi avaliar o coeficiente de digestibilidade aparente (CDA) de sorgo, e determinar o desempenho produtivo, os índices somáticos, os parâmetros hematológicos e a composição centesimal do filé de pacus alimentados com dietas com diferentes níveis de sorgo, além de avaliar o custo da formulação. Para a determinação do CDA da matéria seca (MS), da proteína bruta (PB), do extrato etéreo (EE) e da energia bruta (EB) do sorgo, utilizaram-se 160 pacus, com peso médio de $56,00 \pm 8,04 \mathrm{~g}$, alimentados com dieta-referência e dieta-teste ( $30 \%$ sorgo), acrescidas de $0,1 \%$ de óxido de cromo III. Para avaliação do desempenho, utilizaram-se 180 juvenis de pacu $(10,80 \pm 0,77 \mathrm{~g})$ alimentados com cinco dietas experimentais, em que $0,25,50,75$ e $100 \%$ da energia do milho foi substituída pela do sorgo. Os CDA do sorgo pelo pacu foram: 78,52\% da MS; 74,82\% da PB; 94,36\% de EE; e 77,24\% de EB. Não se observaram diferenças entre as dietas quanto ao desempenho, aos índices somáticos e aos parâmetros hematológicos. Porém, na composição centesimal dos filés, houve diferença entre os tratamentos. O sorgo apresenta CDA semelhante ao do milho e pode substituí-lo integralmente em dietas para juvenis de pacu, além de diminuir o custo da formulação.

Termos para indexação: Piaractus mesopotamicus, Sorghum bicolor, desempenho, digestibilidade aparente, hematologia.

\section{Replacement of corn by sorghum in diets for pacu juvenile}

\begin{abstract}
The objective of this work was to evaluate the apparent digestibility coefficient (ADC) of sorghum, and to determine the growth performance, somatic indices, hematological parameters, and fillet centesimal composition of pacu juveniles fed diets with different levels of sorghum, besides evaluating the cost of the diet formulation. To determine the ADC of dry matter (DM), crude protein (CP), ether extracts (EE), and gross energy (GE) of sorghum, 160 pacus, with 56.00土8.04 g average weight, were used; fish were fed reference and test diets (30\% sorghum) plus $0.1 \%$ of chromium III oxide. For the growth performance trial, 180 juvenile pacu $(10.80 \pm 0.77 \mathrm{~g})$ were used; fish were fed diets containing $0,25,50,75$, and $100 \%$ replacement of corn by sorghum. The ADC of sorghum by fish were: $78.52 \%$ of DM; $74.82 \%$ of CP; $94.36 \%$ of EE; and $77.24 \%$ of GE. There were no differences among diets for the growth performance variables, somatic rates, and hematological parameters. However, for the centesimal composition of fillets, there were differences among treatments. Sorghum shows ADC similar to those of corn and can totally replace it in pacu juvenile diets, besides reducing formulation costs.
\end{abstract}

Index terms: Piaractus mesopotamicus, Sorghum bicolor, performance, apparent digestibility, hematology.

\section{Introdução}

A aquicultura cresceu, nestes últimos anos, de forma mais acentuada do que outras cadeias produtivas tradicionais como a bovinocultura, avicultura e suinocultura, o que resultou no aumento do consumo de pescado que, em 2011, atingiu $11,17 \mathrm{~kg}$ por habitante no Brasil (Anuário Brasileiro da Pesca e Aquicultura, 2014).

Simultaneamente ao crescimento da aquicultura, a produção de rações também expandiu. No entanto, observaram-se oscilações no preço de alimentos convencionais como o milho, principal fonte energética para a alimentação de diferentes espécies animais, além de tradicionalmente destinado ao consumo humano e que, atualmente, é usado também para a produção de biocombustível (Matos et al., 2008; Salla et al., 2010; Cifuentes et al., 2014), o que aumenta sua demanda.

Assim, pesquisas para a substituição parcial ou total do milho na alimentação de peixes são estratégicas e, entre os alimentos energéticos, o sorgo é o que 
apresenta características nutricionais mais semelhantes às do milho (Rostagno, 2011; Nutrient..., 2011), além de ser economicamente viável e com preço competitivo, uma vez que o preço do grão corresponde a aproximadamente $80 \%$ do valor que se paga pelo milho (Acompanhamento..., 2012).

Entretanto, o uso do sorgo na dieta dos animais pode ser limitado pela presença de fatores antinutricionais como o tanino, embora, existam variedades com menores teores, conhecidas como sorgo baixo-tanino, e que possuem nível tolerável deste composto fenólico para os animais monogástricos (Magalhães et al., 2010; Kaijage et al., 2014).

Peixe de clima tropical, o pacu é originário das bacias dos rios Paraná, Paraguai e Uruguai, e possui hábito alimentar onívoro, com tendência a herbívoro, o que permite a utilização de várias fontes proteicas e energéticas em sua alimentação, com fácil adaptação à alimentação artificial e produção comercial (Abimorad \& Carneiro, 2004).

Apesar do potencial do sorgo na alimentação de pacus, ainda não há informações específicas sobre a substituição de milho pelo sorgo em dietas para esta espécie.

O objetivo deste trabalho foi avaliar o coeficiente de digestibilidade aparente (CDA) de sorgo, e determinar o desempenho produtivo, os índices somáticos, os parâmetros hematológicos e a composição centesimal do filé de pacus alimentados com dietas com diferentes níveis de sorgo, além de avaliar o custo da formulação.

\section{Material e Métodos}

O presente trabalho foi desenvolvido no Laboratório de Ecossistemas Aquáticos da Embrapa Meio Ambiente, Jaguariúna, SP. Os procedimentos experimentais utilizados na pesquisa foram aprovados pela Comissão de Ética do Uso de Animais (CEUA) da Embrapa Meio Ambiente (Protocolo n ${ }^{\circ}$ 001/2014).

Foram utilizados 160 juvenis de pacu, com peso médio inicial de $56 \pm 8,04 \mathrm{~g}$, distribuídos em oito gaiolas cilíndricas de polietileno $(80 \mathrm{~L})$, alojadas em dois tanques de polietileno de $2.000 \mathrm{~L}$ cada, com sistema de recirculação de água, temperatura média controlada em torno de $27^{\circ} \mathrm{C}$ e aeração constante. Para a coleta de fezes, foram utilizados quatro aquários de fibra de vidro, com formato cilíndrico e fundo cônico (200 L), para facilitar a decantação do material. Estes aquários foram dotados de aeração contínua e temperatura controlada em torno de $27^{\circ} \mathrm{C}$.

Para as duas rações formuladas - referência e teste -, avaliaram-se os seguintes parâmetros do grão de sorgo: coeficiente de digestibilidade aparente $(\mathrm{CDA} \%)$ da matéria seca (MS); proteína bruta $(\mathrm{PB})$; energia bruta (EB); e extrato etéreo (EE). A dieta-referência foi elaborada de forma a se apresentar isoenergética (3.200 $\mathrm{kcal} \mathrm{kg}^{-1}$ ) e isoproteica (23\% PB), composta por farelo de soja, farelo de trigo e milho. Para a ração-teste, substituiu-se $30 \%$ da ração-referência pelo sorgo. Às dietas referência e teste adicionou-se $0,1 \%$ de óxido de cromo III $\left(\mathrm{Cr}_{2} \mathrm{O}_{3}\right)$ como indicador externo.

O período experimental teve duração de 16 dias, sete dos quais foram destinados à adaptação dos peixes à dieta experimental e nove para coleta de fezes. As oito gaiolas foram divididas em dois grupos de coleta, e as fezes de cada grupo foram coletadas em dias alternados, o que permitiu o descanso dos animais ao manejo estressante.

Os animais foram alimentados sete vezes ao dia, às 10:00, 13:00, 14:00, 14:30, 15:00, 15:30 e 16:00 h, até apresentarem saciedade aparente. Os períodos de alimentação foram definidos a partir do tempo de trânsito gastrintestinal de 20 horas, apresentado por pacus alimentados com dietas com até $9 \%$ de fibra bruta em sua composição, segundo Rodrigues et al. (2010). Ao final da tarde, os peixes eram transferidos para os aquários de coleta, onde permaneciam até a manhã do dia seguinte, e as fezes eram coletadas e armazenadas em placas de Petri a $-20^{\circ} \mathrm{C}$. No final do experimento, as amostras foram descongeladas em temperatura ambiente, centrifugadas a $2.958 \mathrm{~g}$, por $8 \mathrm{~min}$, a $20^{\circ} \mathrm{C}$, desidratadas em estufa de circulação forçada de ar a $55^{\circ} \mathrm{C}$ por 24 horas, moídas e armazenadas sob refrigeração a aproximadamente $5^{\circ} \mathrm{C}$.

A qualidade da água dos tanques de alimentação dos peixes foi monitorada diariamente pela manhã (concentração de oxigênio dissolvido, temperatura e $\mathrm{pH})$ com uso de sonda portátil e semanalmente (nível de amônia), por meio de kits colorimétricos.

As análises da composição químico-bromatológica das rações, fezes, sorgo e filé foram realizadas conforme a metodologia descrita pelaAOAC International (2000). Quantificaram-se o teor de tanino, a fibra bruta (FB) e a matéria mineral (MM) do sorgo. O cromo presente nas rações e nas fezes foi quantificado conforme Silva \& Queiroz (2006). 
As análises de $\mathrm{PB}$, MS e MM foram realizadas pelo Laboratório de Solos e Água (LSA) da Embrapa Meio Ambiente, Jaguariúna, SP. As análises de $\mathrm{Cr}_{2} \mathrm{O}_{3}$ foram realizadas pelo Laboratório de Análise de Solos da Embrapa Agropecuária Oeste, Dourados, MS, e as análises, EE, EB, FB e tanino, pelo Laboratório de Análises (CBO), Campinas, SP.

Após a realização da análise quantitativa do $\mathrm{Cr}_{2} \mathrm{O}_{3} \mathrm{e}$ dos nutrientes das dietas experimentais, calcularam-se os coeficientes de digestibilidade aparente das dietas referência e teste, por meio da equação proposta por Cho \& Slinger (1979) - CDA (\%) $=100-[100(\% \mathrm{Id} /$ $\%$ If $) \times(\% \mathrm{Nf} / \mathrm{Nd})]-$, em que: CDA é o coeficiente de digestibilidade aparente; Id é a concentração de cromo na dieta; If é a concentração de cromo nas fezes; $\mathrm{Nd}$ é o nutriente na dieta; Nf é o nutriente nas fezes.

Os valores de digestibilidade aparente dos nutrientes do ingrediente foram determinados com a equação proposta por Cho \& Slinger $(1979)-\mathrm{CDA}_{\text {ing }}=\left(\mathrm{CD}_{\mathrm{RT}}\right.$ - b.CD $\left.D_{\mathrm{Rb}}\right) / \mathrm{a}$-, em que: $\mathrm{CDA}_{\text {ing }}$ é o coeficiente de digestibilidade aparente do ingrediente; $C_{r t}$ é o coeficiente de digestibilidade aparente da ração com o ingrediente-teste; $\mathrm{CD}_{\mathrm{rb}}$ é o coeficiente de digestibilidade aparente da ração basal; b é a percentagem da ração basal; a é a percentagem do ingrediente-teste.

A partir dos dados de digestibilidade do sorgo nos juvenis de pacu, formularam-se quatro rações, com diferentes níveis de substituição da energia do milho pela do sorgo - 25, 50, 75 e $100 \%$-, em que a ração-controle $(0 \%$ de sorgo) foi a que teve o milho como fonte de energia principal. As rações foram elaboradas de forma a serem isoenergéticas (3.200 kcal $\left.\mathrm{kg}^{-1}\right)$ e isoproteicas (23\% PD), para suprir as exigências nutricionais da espécie, de acordo com Abimorad \& Carneiro (2007) (Tabela 1).

Para a preparação das rações experimentais, os ingredientes foram triturados em moinho tipo faca com peneira de $0,5 \mathrm{~mm}$ e, posteriormente, foram misturados, umedecidos com água a $50^{\circ} \mathrm{C}$ e peletizados em moedor de carne. Posteriormente, os grânulos foram secos em estufa de ventilação forçada de ar a $55^{\circ} \mathrm{C}$, por 24 horas e, em seguida, foram fracionados para obtenção de grânulos de 4 e $6 \mathrm{~mm}$ e armazenados em freezer a $-20^{\circ} \mathrm{C}$.

Para avaliação do desempenho, utilizaramse 180 juvenis de pacu, com peso inicial médio de $10,80 \pm 0,77 \mathrm{~g}$, distribuídos aleatoriamente em 15 aquários de $200 \mathrm{~L}$ cada, acoplados a um sistema de recirculação de água com biofiltro, controle de temperatura em torno $\operatorname{dos} 27^{\circ} \mathrm{C}$ e aeração contínua. Cada aquário foi considerado uma unidade experimental, o que totalizou cinco tratamentos e três repetições.

A avaliação do desempenho teve duração de 60 dias. Durante o experimento, os peixes receberam as dietas quatro vezes ao dia - às 8:00, 11:00, 13:00 e 16:00 h-, em pequenas quantidades, até apresentarem saciedade aparente.

Durante o ensaio, foram aferidos os parâmetros de qualidade da água, como temperatura $\left({ }^{\circ} \mathrm{C}\right)$, oxigênio dissolvido $\left(\mathrm{mg} \mathrm{L}^{-1}\right)$, e $\mathrm{pH}$, com auxílio de sonda

Tabela 1. Composição percentual e calculada de dietas experimentais, com diferentes níveis de inclusão de sorgo $(0,25,50,75$ e $100 \%)$ em substituição ao milho, para juvenis de pacu.

\begin{tabular}{lccccc}
\hline Ingrediente & \multicolumn{5}{c}{ Composição percentual (\%) } \\
\cline { 2 - 6 } & 0 & 25 & 50 & 75 & 100 \\
\hline Farelo de soja & 45,20 & 44,80 & 45,20 & 45,10 & 45,20 \\
Sorgo & - & 8,79 & 17,59 & 26,39 & 35,18 \\
Fubá de milho & 31,48 & 23,61 & 15,74 & 7,87 & - \\
Farelo de trigo & 17,06 & 16,38 & 14,91 & 13,83 & 12,56 \\
Óleo de soja & 1,62 & 2,01 & 2,40 & 2,85 & 3,28 \\
Fosfato bicálcico & 3,38 & 3,00 & 2,60 & 2,25 & 1,90 \\
Calcário & 0,20 & 0,35 & 0,52 & 0,66 & 0,83 \\
L-Lisina (78\%) & 0,37 & 0,37 & 0,36 & 0,37 & 0,37 \\
DL-Metionina (99\%) & 0,07 & 0,07 & 0,06 & 0,06 & 0,06 \\
Cloreto de Sódio (NaCl) & 0,10 & 0,10 & 0,10 & 0,10 & 0,10 \\
Premix vitamínico e mineral ${ }^{(1)}$ & 0,50 & 0,50 & 0,50 & 0,50 & 0,50 \\
Butil-hidroxi-tolueno & 0,02 & 0,02 & 0,02 & 0,02 & 0,02 \\
\hline Total & 100,0 & 100,0 & 100,0 & 100,0 & 100,0 \\
\hline Custo da formulação ${ }^{(2)}\left(\mathrm{R} \$ / \mathrm{kg}^{\prime}\right)$ & 0,91 & 0,89 & 0,88 & 0,87 & 0,86 \\
\hline Composição química calculada $(\%)$ & & & & \\
Proteína bruta & 25,58 & 25,56 & 25,77 & 25,82 & 25,92 \\
Energia digestível (kcal kg-1) & $3.200,3$ & $3.199,3$ & $3.199,1$ & $3.200,4$ & $3.200,1$ \\
Proteína digestível & 23,15 & 23,01 & 23,00 & 23,01 & 22,99 \\
Metionina & 0,38 & 0,38 & 0,38 & 0,38 & 0,38 \\
Lisina & 1,65 & 1,64 & 1,64 & 1,64 & 1,64 \\
Extrato etéreo & 4,12 & 4,85 & 5,56 & 6,34 & 7,09 \\
Fibra bruta & 4,58 & 4,46 & 4,31 & 4,18 & 4,03 \\
Cálcio & 1,06 & 1,05 & 1,05 & 1,04 & 1,05 \\
Fósforo disponível & 0,70 & 0,70 & 0,70 & 0,70 & 0,70 \\
\hline
\end{tabular}

(1)Suplemento mineral e vitamínico (composição por quilograma de ração): selênio, $75 \mathrm{mg}$; ferro, $15 \mathrm{~g}$; cobre, $1.250 \mathrm{mg}$; manganês, $3.750 \mathrm{mg}$; zinco, $17,5 \mathrm{~g}$; cobalto, $50 \mathrm{mg}$; iodo, $100 \mathrm{mg}$; niacina, $8.750 \mathrm{mg}$; ácido fólico, $625 \mathrm{mg}$; ácido pantotênico, $7.500 \mathrm{mg}$; biotina, $50 \mathrm{mg}$; vitamina C, $37,5 \mathrm{~g}$; colina, $100 \mathrm{~g}$; inositol, $12,5 \mathrm{~g}$; vitamina A, $1.750 .000 \mathrm{UI}$; vitamina D3, 375.000 UI; vitamina E, 20.000 UI; vitamina $\mathrm{K} 3,500 \mathrm{mg}$; vitamina B1, $2.000 \mathrm{mg}$; vitamina B2, $2.500 \mathrm{mg}$; vitamina B6, $2.500 \mathrm{mg}$; vitamina B12, $5.000 \mu \mathrm{g} .{ }^{(2)}$ Calculados a partir dos preços vigentes em janeiro de 2015. 
multiparâmetro portátil YSI-566 (YSI Inc., Yellow Spring, OH, EUA), diariamente pela manhã, e os teores de amônia, semanalmente, por kit colorimétrico DR 3900 (Hach, Loveland, CO, EUA).

Os valores dos parâmetros de qualidade da água durante o ensaio de digestibilidade, foram: temperatura, $26,30 \pm 0,33^{\circ} \mathrm{C}$; oxigênio dissolvido, $7,75 \pm 0,96 \mathrm{mg} \mathrm{L}^{-1} ; \mathrm{pH}, 7,67 \pm 0,23$; e amônia total, $0,08 \pm 0,01 \mathrm{mg} \mathrm{L}^{-1}$. No ensaio de desempenho, foram: temperatura, $25,49 \pm 0,43^{\circ} \mathrm{C}$; oxigênio dissolvido, $5,89 \pm 0,13 \mathrm{mg} \mathrm{L} \mathrm{L}^{-1} ; \mathrm{pH}, \quad 7,25 \pm 0,25 ;$ e amônia total, $0,03 \pm 0,014 \mathrm{mg} \mathrm{L}^{-1}$. Logo, estes parâmetros mantiveram-se em níveis adequados para a espécie (Mylonas et al., 2005). Durante o período experimental dos ensaios de digestibilidade e desempenho, não houve mortalidade dos peixes avaliados para os respectivos tratamentos.

Após o período experimental, os peixes foram anestesiados com benzocaína a $100 \mathrm{mg} \mathrm{L}^{-1}$, medidos e pesados para a determinação dos parâmetros de desempenho, que foram: ganho de peso, GP $(\mathrm{g})=$ peso final (g) - peso inicial (g); taxa de crescimento específico, TCE $(\%)=100 \times[(\ln$ peso final $-\ln$ peso inicial) / período experimental]; consumo de ração, $\mathrm{CR}(\mathrm{g})=$ alimento consumido total $(\mathrm{g}) /$ período experimental; conversão alimentar aparente, $\mathrm{CAA}=$ alimento fornecido (g) / ganho de peso (g); taxa de eficiência proteica, TEP $(\%)=100 \mathrm{x}$ ganho de peso $(\mathrm{g})$ / proteína bruta consumida (g); e sobrevivência.

$\mathrm{Na}$ avaliação dos parâmetros hematológicos, colheu-se o sangue de nove peixes por tratamento, por meio de punção do vaso caudal, com uso de seringas e agulhas umedecidas internamente com EDTA a 3\%. Determinaram-se: o percentual de micro-hematócritos, pelo método de Goldenfarb et al. (1971), os níveis de hemoglobina, pelo método de cianometa-hemoglobina, de Collier (1944); e a concentração de hemoglobina corpuscular média (CHCM) (Wintrobe, 1934).

Em seguida, estes mesmos peixes passaram por eutanásia com superdosagem de benzocaína (200 $\left.\mathrm{mg} \mathrm{L}^{-1}\right)$ e seus fígados, tecidos adiposos e os filés foram coletados para a realização dos seguintes cálculos: índice hepatossomático, IHS $(\%)=100$ $\mathrm{x}$ [peso do fígado (g)/ peso corporal (g)]; índice de gordura-víscerossomática, IGVS (\%) $=100 \mathrm{x}$ [peso da gordura visceral (g)/ peso corporal (g)]; e composição centesimal do filé.
$\mathrm{O}$ custo por quilo de peixe produzido $\left(\mathrm{R} \$ \mathrm{~kg}^{-1}\right.$ de ganho de peso) foi estimado pelo custo dos ingredientes da ração formulada, multiplicado pela conversão alimentar. Os valores dos ingredientes foram obtidos em consulta aos fabricantes de rações do Estado de São Paulo, com base nos preços vigentes em janeiro de 2015.

Para avaliação do desempenho produtivo, os dados foram submetidos à análise de variância a $5 \%$ de probabilidade, e quando significativas, as médias foram submetidas à análise de regressão polinomial a $5 \%$ de probabilidade. Para avaliação dos índices somáticos, dos parâmetros hematológicos e da composição centesimal, os dados foram submetidos à análise de variância a $5 \%$ de probabilidade, e as médias, quando significativas, foram submetidas ao teste de Duncan a $5 \%$ de probabilidade, com o programa estatístico SAS (SAS Institute, Cary, NC, EUA).

\section{Resultados e Discussão}

As médias de $\mathrm{CDA}$, quanto aos nutrientes e à energia do sorgo, foram: $78,52 \%$ fração de MS; 74,82\%, PB; 94,36\%, EE; e 77,24\%, EB (Tabela 2). Estes resultados foram inferiores aos encontrados por Abimorad \& Carneiro (2004), que observaram digestibilidade da fração de $\mathrm{PB}$ de 92,93\% e EB de 93,36\%, quando avaliaram o CDA do sorgo para pacu. Estas diferenças de CDA podem ter sido influenciadas pela variação na composição químico-bromatológica das cultivares de sorgo, bem como pela diferença nos pesos médios dos peixes utilizados pelos autores citados $(250 \mathrm{~g})$ e os do presente estudo (56 g). De acordo com Lanna et al. (2004), o aumento do intestino do peixe é proporcional ao seu tamanho e, por isso, a digestibilidade da dieta

Tabela 2. Composição químico-bromatológica do sorgo e valores médios dos coeficientes de digestibilidade aparente $(\mathrm{CDA} \%)$ da matéria seca, proteína bruta, energia bruta e extrato etéreo do sorgo, por juvenis de pacu (valores com base na matéria seca).

\begin{tabular}{lcc}
\hline Nutriente & Composição & CDA (\%) \\
\hline Matéria seca (\%) & 92,90 & 78,52 \\
Proteína bruta (\%) & 10,01 & 74,82 \\
Energia bruta (kcal kg ${ }^{-1}$ ) & 3957 & 77,24 \\
Extrato etéreo (\%) & 7,46 & 94,36 \\
Fibra bruta (\%) & 1,22 & - \\
Tanino (\%) & 0,42 & - \\
\hline
\end{tabular}


pode aumentar de acordo com sua fase de crescimento (principalmente em peixes onívoros e herbívoros).

Outros fatores, como os níveis de fibra presentes na dieta e a proporção de amilose e amilopectina do amido no grão, podem ter influenciado a digestibilidade da dieta pelos peixes (Guimarães et al., 2011). Além disso, a fração fibrosa que compõe os alimentos influencia a digestibilidade da energia e o aproveitamento de outros nutrientes da dieta (Rodrigues et al., 2010).

Em comparação a outros alimentos energéticos avaliados para o pacu, o CDA do sorgo, observado no presente estudo, foi inferior ao do farelo de trigo e milho quanto à $\mathrm{PB}(87,7 \%$ e $85,8 \%)$, e próximo ao do sorgo quanto à $\mathrm{EB}(74,4 \%$ e $75,8 \%)$ respectivamente (Abimorad et al., 2008). No caso do milho e sorgo, o CDA das frações de PB e EB encontram-se muito próximos, e essa diferença, observada entre os grãos, pode estar relacionada tanto com a proporção do amido presente nestes ingredientes, quanto no tipo de proteína que envolve o amido, pois, quanto maior a proporção de amido no endosperma, menor a degradação física e enzimática do amido (Antunes et al., 2006; Marques et al., 2007).

O sorgo apresenta maior composição de amido $(63,24 \%)$ do que o milho $(62,66 \%)$ (Rostagno, 2011) e, consequentemente, maior distribuição das proteínas ao redor do amido do endosperma. Assim, as prolaminas presentes no sorgo podem formar ligações entre si e diminuir a digestibilidade do amido do endosperma e da proteína que o envolve (Antunes et al., 2006; Marques et al., 2007), o que influencia a digestibilidade do alimento e, consequentemente, o desempenho dos animais.

A substituição do milho pelo sorgo, em dietas para pacu, não proporcionou diferenças quanto aos parâmetros de desempenho produtivo avaliados - GP, CAA, TCE e TEP (Tabela 3).

Segundo Wagner et al. (2009), espécies herbívoras e onívoras apresentam capacidade de adaptar morfológica e fisiologicamente suas estruturas e propriedades absortivas do sistema digestório, em resposta às mudanças da dieta. Essas adaptações aos alimentos influenciam a disponibilidade de enzimas digestivas e a capacidade de transporte transepitelial dos nutrientes do trato digestório (Bakke et al., 2010), o que possibilita maior digestão, absorção e conversão dos nutrientes do alimento.

A composição do amido no grão utilizado na confecção das rações e fatores, como a densidade de estocagem, frequência de arraçoamento e período experimental, também podem influenciar o desempenho dos peixes e sua resposta às dietas (Lanna et al., 2004; Abimorad et al., 2009; Rodrigues et al., 2010).

Não se observaram diferenças entre os tratamentos, quanto aos índices somáticos e hematológicos - IHS, IGVS, hematócrito, hemoglobina e CHCM (Tabela 4). Uma vez que as dietas experimentais foram formuladas para serem isoproteicas, isonergéticas, e também com valores similares de metionina, lisina, fibra bruta, cálcio e fósforo disponível, estes resultados eram esperados, pois a única mudança nas dietas experimentais foi com o alimento-teste, que se mostrou equivalente ao milho nas respostas de desempenho.

No presente trabalho, a substituição do milho pelo sorgo não influenciou os valores médios de hematócrito, hemoglobina e CHCM. Estes valores foram similares aos relatados por Tavares-Dias \& Mataqueiro (2004) - hemoglobina $\left(6,6 \mathrm{~g} \mathrm{dL}^{-1}\right)$, CHCM $(21,4 \%)$ e hematócrito $(31,9 \%)$, para pacus produzidos em viveiro - , o que indica que os níveis de hemoglobina, $\mathrm{CHCM}$ e

Tabela 3. Valores médios de desempenho produtivo de juvenis de pacu, alimentados com dietas com diferentes níveis de sorgo em substituição ao milho, e custo da formulação.

\begin{tabular}{|c|c|c|c|c|c|}
\hline \multirow[t]{2}{*}{ Parâmetro } & \multicolumn{5}{|c|}{ Substituição (\%) } \\
\hline & 0 & 25 & 50 & 75 & 100 \\
\hline PI (g) & $10,91 \pm 0,16$ & $10,79 \pm 0,15$ & $10,83 \pm 0,11$ & $10,69 \pm 0,22$ & $10,75 \pm 0,03$ \\
\hline GP (g) & $22,27 \pm 5,36$ & $22,02 \pm 0,70$ & $24,71 \pm 5,85$ & $22,68 \pm 3,38$ & $22,17 \pm 4,32$ \\
\hline CAA & $1,38 \pm 0,39$ & $1,30 \pm 0,17$ & $1,22 \pm 0,19$ & $1,30 \pm 0,17$ & $1,31 \pm 0,26$ \\
\hline TCE (\%) & $1,84 \pm 0,28$ & $1,85 \pm 0,03$ & $1,97 \pm 0,26$ & $1,90 \pm 0,20$ & $1,86 \pm 0,23$ \\
\hline TEP (\%) & $1,43 \pm 0,34$ & $1,41 \pm 0,04$ & $1,58 \pm 0,37$ & $1,46 \pm 0,22$ & $1,42 \pm 0,42$ \\
\hline Custo & $1,25 \pm 0,36$ & $1,16 \pm 0,15$ & $1,07 \pm 0,17$ & $1,13 \pm 0,15$ & $1,12 \pm 0,22$ \\
\hline
\end{tabular}

PI, peso inicial; GP, ganho de peso; CAA, conversão alimentar aparente; TCE, taxa de crescimento específico; TEP, taxa de eficiência proteica; custo (R $\mathrm{kg}^{-1}$ de ganho de peso), custo da formulação multiplicado pela conversão alimentar aparente, com os preços vigentes em janeiro de 2015. 
hematócrito do presente trabalho estão dentro da faixa observada para a espécie.

A composição centesimal do filé não apresentou diferença significativa entre os tratamentos sobre o percentual de MS. Porém, apresentou diferenças em relação aos parâmetros $\mathrm{PB}, \mathrm{EE}$ e MM (Tabela 5).

A deposição de PB foi superior nos filés de peixes alimentados com a dieta-controle e com a de $25 \%$ de substituição do milho pelo sorgo, em comparação aos que receberam dietas com $75 \%$. Porém, os peixes alimentados com a dieta-controle e com o tratamento de $25 \%$ de substituição não diferiram dos que receberam as dietas com 50 e $100 \%$ de substituição do milho pelo sorgo.

Em relação ao extrato etéreo, os animais que receberam as dietas com 25 e 100\% de substituição do milho pelo sorgo apresentaram valores superiores aos demais tratamentos, mas não diferiram entre si, e os que receberam as dietas com 50 e $75 \%$ de substituição do milho pelo sorgo não diferiram, porém foram superiores ao controle.

$\mathrm{O}$ teor de MM dos filés de juvenis de pacu, alimentados com a dieta de $75 \%$ de substituição do milho pelo sorgo, foi superior ao da dieta com
$25 \%$ de substituição, porém não diferiu dos demais tratamentos.

De acordo com Aiura \& Carvalho (2007) fontes de tanino na alimentação de peixes proporcionam menor deposição de gordura na carcaça, vísceras e filés. O tanino tem a capacidade de interferir no uso dos lipídios que compõem a dieta, pois se complexa com as enzimas digestivas e contribui para a menor deposição de lipídio corporal (Benevides et al., 2011). Assim, constata-se que sorgo com apenas $0,42 \%$ de taninos totais não apresenta a capacidade de alterar a deposição lipídica dos filés de pacu.

$\mathrm{O}$ custo da ração por quilo de ganho de peso foi menor $(14,4 \%)$, quando se utilizou $50 \%$ de substituição do milho pelo sorgo, em comparação com a ração-controle; em comparação aos níveis de 25,75 e $100 \%$, a redução apresentada foi de 7,2, 9,6 e 10,4\%, respectivamente. Ressalta-se, portanto que, para todos os níveis de substituição, o uso do sorgo reduziu o custo da formulação.

O sorgo pode substituir integralmente o milho nas dietas de juvenis de pacu, com respostas de desempenho, índices somáticos e parâmetros hematológicos semelhantes entre os níveis de substituição avaliados.

Tabela 4. Valores médios dos índices somáticos e hematológicos, de juvenis de pacu, alimentados com dietas com diferentes níveis de sorgo em substituição ao milho.

\begin{tabular}{|c|c|c|c|c|c|}
\hline \multirow[t]{2}{*}{ Parâmetro } & \multicolumn{5}{|c|}{ Substituição (\%) } \\
\hline & 0 & 25 & 50 & 75 & 100 \\
\hline IHS (\%) & $0,95 \pm 0,18$ & $1,15 \pm 0,26$ & $1,16 \pm 0,24$ & $1,01 \pm 0,16$ & $1,12 \pm 0,24$ \\
\hline IGVS (\%) & $1,61 \pm 0,64$ & $1,60 \pm 0,35$ & $1,79 \pm 0,12$ & $1,64 \pm 0,22$ & $1,61 \pm 0,10$ \\
\hline Htc $(\%)$ & $31,0 \pm 2,00$ & $32,0 \pm 2,00$ & $30,0 \pm 3,00$ & $31,0 \pm 2,00$ & $32,0 \pm 2,00$ \\
\hline $\mathrm{Hb}\left(\mathrm{g} \mathrm{dL}^{-1}\right)$ & $5,56 \pm 0,35$ & $5,93 \pm 0,54$ & $5,76 \pm 0,27$ & $5,85 \pm 0,53$ & $5,46 \pm 0,67$ \\
\hline CHCM (\%) & $17,93 \pm 0,74$ & $18,46 \pm 0,97$ & $19,03 \pm 1,67$ & $18,74 \pm 2,18$ & $17,10 \pm 1,45$ \\
\hline
\end{tabular}

IHS, índice hepatossomático; IGVS, índice de gordura-víscero-somática; Htc, hematócrito; Hb, hemoglobina; e CHCM, concentração de hemoglobina corpuscular média.

Tabela 5. Composição centesimal de filés de juvenis de pacu, alimentados com dietas com diferentes níveis de sorgo em substituição ao milho (valores com base na matéria seca) ${ }^{(1)}$.

\begin{tabular}{lcccc}
\hline Parâmetro (\%) & \multicolumn{4}{c}{ Substituição (\%) } \\
\cline { 2 - 5 } & 0 & 25 & 50 & 35 \\
\hline MS & $32,49 \pm 0,11 \mathrm{a}$ & $31,44 \pm 0,76 \mathrm{a}$ & $32,37 \pm 0,39 \mathrm{a}$ & $32,66 \pm 0,48 \mathrm{a}$ \\
PB & $75,83 \pm 10,73 \mathrm{a}$ & $74,17 \pm 2,38 \mathrm{a}$ & $73,33 \pm 3,88 \mathrm{ab}$ & $65,21 \pm 2,60 \mathrm{~b}$ \\
EE & $4,17 \pm 0,39 \mathrm{c}$ & $6,41 \pm 0,17 \mathrm{a}$ & $10,01 \pm 0,19 \mathrm{~b}$ & $11,05 \pm 0,17 \mathrm{~b}$ \\
MM & $6,67 \pm 0,34 \mathrm{ab}$ & $6,83 \pm 0,04 \mathrm{~b}$ & $6,52 \pm 0,37 \mathrm{ab}$ & $6,17 \pm 0,22 \mathrm{a}$ \\
\hline
\end{tabular}

${ }^{(1)}$ Médias seguidas por letras iguais, nas linhas, não diferem pelo teste de Duncan, a 5\% de probabilidade. MS, matéria seca; PB, proteína bruta; EE, extrato etéreo; MM, matéria mineral. 
Pela elevada capacidade do pacu de aproveitar carboidratos como fonte de energia e pela sazonalidade do preço do milho em determinados períodos do ano, verifica-se que o sorgo é uma alternativa segura e viável economicamente para a produção de rações para a espécie.

\section{Conclusões}

1. Em dietas para juvenis de pacu, o sorgo apresenta coeficiente de digestibilidade aparente semelhante ao do milho, quanto aos nutrientes e à energia.

2. O sorgo pode substituir integralmente o milho em dietas para juvenis de pacu, sem causar alterações negativas ao desempenho produtivo, índices somáticos e hematologia.

3. A substituição do milho pelo sorgo reduz o custo da formulação da dieta para juvenis de pacu e o custo de produção.

\section{Agradecimentos}

À Coordenação de Aperfeiçoamento de Pessoal de Nível Superior (Capes), por concessão de bolsa.

\section{Referências}

ABIMORAD, E.G.; CARNEIRO, D.J. Digestibility and performance of pacu (Piaractus mesopotamicus) juveniles fed diets containing different protein, lipid and carbohydrate levels. Aquaculture Nutrition, v.13, p.1-9, 2007. DOI: 10.1111/j.13652095.2007.00438.x.

ABIMORAD, E.G.; CARNEIRO, D.J. Métodos de coleta de fezes e determinação dos coeficientes de digestibilidade da fração protéica e da energia de alimentos para o pacu, Piaractus mesopotamicus (Holmberg, 1887). Revista Brasileira de Zootecnia, v.33, p.1101-1109, 2004. DOI: 10.1590/S1516-35982004000500001.

ABIMORAD, E.G.; FAVERO, G.C.; CASTELLANI, D.; GARCIA, F.; CARNEIRO, D.J. Dietary supplementation of lysine and/or methionine on performance, nitrogen retention and excretion in pacu Piaractus mesopotamicus reared in cages. Aquaculture, v.295, p.266-270, 2009. DOI: 10.1016/j.aquaculture.2009.07.001.

ABIMORAD, E.G.; SQUASSONI, G.H.; CARNEIRO, D.J. Apparent digestibility of protein, energy, and amino acids in some selected feed ingredients for pacu Piaractus mesopotamicus. Aquaculture Nutrition, v.14, p.374-380, 2008. DOI: 10.1111/J.13 65-2095.2007.00544.x.

ACOMPANHAMENTO da safra brasileira: cana-de-açúcar, safra 2012/2013, terceiro levantamento. Brasília: Conab, 2012. Disponível em: <http://www.conab.gov.br/OlalaCMS/ uploads/arquivos/12_12_12_10_34_43_boletim_cana_ portugues_12_2012.pdf $>$. Acesso em: 10 jan. 2014.
AIURA, F.S.; CARVALHO, M.R.B. de. Body lipid deposition in Nile tilapia fed on rations containing tannin. Pesquisa Agropecuária Brasileira, v.42, p.50-56, 2007. DOI: 10.1590/ S0100-204X2007000100007.

ANTUNES, R.C.; RODRIGUEZ, N.M.; GONÇALVES, L.C.; RODRIGUES, J.A.S.; BAIÃO, N.C.; PEREIRA, L.G.R.; LARA, L.J. Valor nutritivo de grãos de sorgo com diferentes texturas do endosperma para frangos de corte. Arquivo Brasileiro de Medicina Veterinária e Zootecnia, v.58, p.877-883, 2006. DOI: $10.1590 / \mathrm{S} 0102-09352006000500025$.

ANUÁRIO BRASILEIRO DA PESCA E AQUICULTURA. Florianópolis: Associação Cultural e Educacional do Brasil, v. 1, jan. 2014. Disponível em: <http://formsus.datasus.gov.br/ novoimgarq/16061/2489520_218117.pdf >. Acesso em: 10 fev. 2015.

AOAC INTERNATIONAL. Official methods of analysis of AOAC International. $17^{\text {th }}$ ed. Gaithersburg, 2000.

BAKKE, A.M.; GLOVER, C.; KROGDAHL, Â. Feeding, digestion and absorption of nutrients. Fish Physiology, v.30, p.57-110, 2010. DOI: 10.1016/S1546-5098(10)03002-5.

BENEVIDES, C.M. de J.; SOUZA, M.V.; SOUZA, R.D.B.; LOPES, M.V. Fatores antinutricionais em alimentos: revisão. Segurança Alimentar e Nutricional, v.18, p.67-79, 2011.

CHO, C.Y.; SLINGER, S.J. Apparent digestibility measurement in feedstuffs for rainbow trout. In: SYMPOSIUM ON FINFISH NUTRITION AND FEED TECHNOLOGY, 1978, Hamburg. Proceedings. Berlin: Heenemann Verlagsgesellschaft, 1979. v.2, p.239-247.

CIFUENTES, R.; BRESSANI, R.; ROLZ, C. The potential of sweet sorghum as a source of ethanol and protein. Energy for Sustainable Development, v.21, p.13-19, 2014. DOI: 10.1016/j. esd.2014.04.002.

COLLIER, H.B. Standardization of blood hemoglobin determinations. Canadian Medical Association Journal, v.50, p.550-552, 1944.

GOLDENFARB, P.B.; BOWYER, F.P.; HALL, E.; BROSIOUS, E. Reproducibility in the hematology laboratory: the microhematocrit determinations. American Journal of Clinical Pathology, v.56, p.35-39, 1971.

GUIMARÃES, I.G.; PEZZATO, L.E.; BARROS, M.M.; TACHIBANA, L.; FERNANDES, R. do N. Digestibilidade do amido e disponibilidade de $\mathrm{Ca}$ e $\mathrm{P}$ em alimentos energéticos extrusados para a tilápiadoNilo (Oreochromis niloticus). Ciência Animal Brasileira, v.12, p.415-419, 2011. DOI: 10.5216/cab. v12i3.4483.

KAIJAGE, J.T.; MUTAYOBA, S.K.; KATULE, A. Chemical composition and nutritive value of Tanzanian grain sorghum varieties. Livestock Research for Rural Development, v.26, article 177, 2014.

LANNA, E.A.T.; PEZZATO, L.E.; CECON, P.R.; FURUYA, W.M.; BOMFIM, M.A.D. Digestibilidade aparente e trânsito gastrintestinal em tilápia do Nilo(Oreochromis niloticus), em função da fibra bruta da dieta. Revista Brasileira de Zootecnia, v.33, p.2186-2192, 2004. DOI: 10.1590/S1516-35982004000900002. 
MAGALHÃES， R.T.; GONÇALVES， L.C.; BORGES， I.; RODRIGUES, J.A.S.; FONSECA, J.F. Produção e composição bromatológica de vinte e cinco genótipos de sorgo (Sorghum bicolor (L.) Moench). Arquivo Brasileiro de Medicina Veterinária e Zootecnia, v.62, p.747-751, 2010. DOI: 10.1590/ S0102-09352010000300034.

MARQUES, B.M.F.P.P.; ROSA, G.B.; HAUSCHILD, L.; CARVALHO, A.D'A.; LOVATTO, P.A. Substituição de milho por sorgo baixo tanino em dietas para suínos: digestibilidade e metabolismo. Arquivo Brasileiro de Medicina Veterinária e Zootecnia, v.59, p.767-772, 2007. DOI: 10.1590/ S0102-09352007000300031.

MATOS, M.A.; NINAUT, E.S.; CAIADO, R.C.; SALVI, J.V. A elevação dos preços das commodities agrícolas e a questão da agroenergia. Informações Econômicas, v.38, p.68-83, 2008.

MYLONAS, C.C.; CARDINALETTI, G.; SIGELAKI, I.; POLZONETTI-MAGNI, A. Comparative efficacy of clove oil and 2-phenoxyethanol as anesthetics in the aquaculture of European sea bass (Dicentrarchus labrax) and gilthead sea bream (Sparus aurata) at different temperatures. Aquaculture, v.246, p.467-481, 2005. DOI: 10.1016/j. aquaculture.2005.02.046.

NUTRIENT requirements of fish and shrimp. Washington, DC.: National Academy Press, 2011. 360p.

RODRIGUES, L.A.; FABREGAT, T.E.H.P.; FERNANDES, J.B.K.; NASCIMENTO, T.M.T.; SAKOMURA, N.K. Digestibilidade e tempo de trânsito gastrintestinal de dietas contendo níveis crescentes de fibra bruta para pacu. Acta Scientiarum. Animal Science, v.32, p.169-173, 2010. DOI: 10.4025/actascianimsci. v32i2.8625.

ROSTAGNO, H.S. (Ed.). Tabelas brasileiras para aves e suínos: composição de alimentos e exigências nutricionais. 3.ed. Viçosa: Ed. da UFV, 2011. 252p.

SALLA, D.A.; FURLANETO, F. de P.B.; CABELLO, C.; KANTHACK, R.A.D. Estudo energético da produção de biocombustível a partir do milho. Ciência Rural, v.40, p.2017-2022, 2010. DOI: 10.1590/S0103-84782010005000142.

SILVA, D.J.; QUEIROZ, A.C. de. Análise de alimentos: métodos químicos e biológicos. 3.ed. Viçosa: Ed. da UFV, 2006. 235p.

TAVARES-DIAS, M.; MATAQUEIRO, M.I. Características hematológicas, bioquímicas e biométricas de Piaractus mesopotamicus Holmberg, 1887 (Osteichthyes: Characidae) oriundos de cultivo intensivo. Acta Scientiarum. Biological Sciences, v.26, p.157-162, 2004. DOI: 10.4025/actascibiolsci. v26i2.1647.

WAGNER, C.E.; MCINTYRE, P.B.; BUELS, K.S.; GILBERT, D.M.; MICHEL, E. Diet predicts intestine length in Lake Tanganyikas's cichlid fishes. Functional Ecology, v.23, p.1122-1131, 2009. DOI: 10.1111/j.1365-2435.2009.01589.x.

WINTROBE, M.M. Variations in the science and hemoglobin content of erythrocytes in the blood of various vertebrates. Folia Haematologica, v.51, p.32-49, 1934.

Recebido em 3 de agosto de 2015 e aprovado em 18 de novembro de 2015 